\title{
Percepções do Homossexual Masculino: Sociedade, Família e Amizades
}

\author{
Crístofer Batista da Costa ${ }^{1}$ \\ Programa de Pós-Graduação em Psicologia da Universidade do Vale do Rio dos Sinos, \\ São Leopoldo, RS, Brasil \\ Mariana Rodrigues Machado \\ Programa de Pós-Graduação em Psicologia Clínica da Universidade do Vale do Rio \\ dos Sinos, São Leopoldo, RS, Brasil \\ Márcia Fortes Wagner \\ Escola de Psicologia e Coordenação da Especialização em Terapia \\ Cognitivo-Comportamental da Faculdade Meridional, Passo Fundo, Brasil, RS
}

\section{Resumo}

O objetivo deste estudo foi compreender as percepções do homossexual masculino sobre a sua orientação sexual e as possíveis repercussões da sua homossexualidade no contexto familiar e social onde vive. Trata-se de uma pesquisa qualitativa com delineamento exploratório e descritivo. Os dados foram coletados por meio de entrevista semiestruturada contendo questões norteadoras focando os sentimentos, os comportamentos e as percepções dos participantes sobre sua homossexualidade e sobre as relações com familiares, colegas de trabalho e amigos. Os dados foram submetidos à análise de conteúdo, por meio da qual emergiram quatro eixos temáticos: amizade, vínculo para ser quem realmente somos; comportamentos e sentimentos do homossexual; percepção pessoal da homossexualidade e revelação para a família; repercussões da revelação da homossexualidade na família. A partir dos resultados, compreende-se que o preconceito contra homossexuais está presente em determinados espaços, como o ambiente de trabalho; as relações familiares e de amizade emergiram como fator de proteção e a percepção do próprio indivíduo sobre sua homossexualidade pode contribuir para a manutenção ou para a atualização dos tipos de interação que estabelece.

Palavras-chave: Homossexualidade, comportamento sexual, relações familiares, preconceito.

\section{Perceptions of the Male Homossexual: Society, Family, and Friendships}

\begin{abstract}
The objective of this study was to comprehend the perceptions of the male homosexual about his sexual orientation and the possible repercussions of his homosexuality in family and social contexts. This is a qualitative research with an exploratory and descriptive design. Data were collected through semistructured interview, which contained guiding questions focusing on the participant's feelings, behaviors and perceptions about his homosexuality and about his relationships with family members, workmates, and friends. Data were submitted to content analysis, generating four thematic axes: friendship, the bond
\end{abstract}

Endereço para correspondência: Rua Coronel Corte Real, 913/204, Petrópolis, Porto Alegre, RS, Brasil 90630-080. Fone: (54) 9161-3134; Fax: (51) 3590-8123. E-mail: cristoferbatistadacosta@gmail.com, mariana. rmachado@yahoo.com.bre mwagner@imed.edu.br 
to be who we are; behaviors and feelings of the homosexual; personal perception about homosexuality and revelation to the family; repercussion on revealing the homosexuality for the family. Drawing from the results, we understood that prejudice against homosexuals is present in determined spaces, such as the working environment; family relations and friendships emerged as protection factors and the perception of the individual about his homosexuality may contribute to maintaining or updating the types of relationships established.

Keywords: Homosexuality, sexual behavior, family relations, prejudice.

\section{Percepciónes del Homosexual Masculino: Sociedad, Familia y Amistades}

\section{Resumen}

El objetivo de este estudio fue comprender las percepciones homosexuales masculinos de su orientación sexual y las posibles repercusiones de su homosexualidad en el contexto familiar y social en el que vive. Se trata de una investigación cualitativa con un diseño exploratorio y descriptivo. Los datos fueron recolectados a través de entrevista semi-estructurada que contenía preguntas de orientación se centra en los sentimientos, comportamientos y percepciones de los participantes sobre su homosexualidad y la relación con los miembros de la familia, compañeros de trabajo y amigos. Los datos fueron sometidos a análisis de contenido, a través del cual surgieron cuatro temas: la amistad, la relación sea lo que realmente somos; comportamientos y emociones de homosexual; percepción personal de la homosexualidad y la revelación de la familia; homosexualidad revelación del impacto en la familia. De los resultados, se entiende que el prejuicio contra los homosexuales está presente en ciertas áreas, tales como el medio ambiente de trabajo; las relaciones familiares y de amistad surgió como un factor protector y la percepción del individuo sobre su homosexualidad puede contribuir al mantenimiento o la actualización de los tipos de interacción que establece.

Palabras clave: Homosexualidad, comportamiento sexual, relaciones familiares, prejuicio.

A sexualidade é variável em diversos sentidos, tomando formas diferentes no interior dos próprios indivíduos, dentro dos gêneros, nas sociedades e operando por meio de um conjunto heterogêneo de discursos e práticas sociais. Como resultado social, diferencia-se de gênero para gênero, de classe para classe e de sociedade para sociedade (Costa, 2007; Foucault, 2006; V. G. Silva, 2007).

Além disso, a sexualidade pode ser entendida também como uma condição humana que o indivíduo traz desde o seu nascimento e que integra o fator natural, inalienável e imprescritível (Dias, 2005). Noutra direção, Louro (2008) refere que a construção da sexualidade e do gênero acontece ao longo da vida, de maneira contínua sendo, portanto, ensinada. Para o autor, a definição de masculino e feminino não é feita no nascimento e posterior classificação biológi- ca do corpo como macho ou fêmea. São procedimentos que articulam elementos tão diversos de regulação da vida social, quanto discursos, instituições, formas arquitetônicas, enunciados científicos, proposições morais e filosóficas. $\mathrm{O}$ indivíduo aprende a se identificar e viver o gênero e a sexualidade dentro da sua cultura, relacionando-se com o outro, tomando-o como referência e vivendo um processo de reconhecimento (Louro, 2008).

Nesse processo de reconhecimento entre iguais, revela-se, muitas vezes, a homossexualidade (Balderston, 2014). O referido autor examinou os vínculos poéticos a partir de um poema de Carlos Pellicer, encontrando a comunicação de segredos do amor homossexual que, por meio da poesia, passavam do privado ao público. Através das poesias, revelava-se uma atmosfera de segredos, silêncios e suspeitas a respeito da 
comunicação de algo secreto, do amor homossexual, transformando o silêncio em tema de incessante conversa e livre expressão.

Ao longo da história, a sociedade organizou-se através da voz do homem branco heterossexual. A construção das representações sociais nascem dessa visão de mundo, que detém e regula espaços culturais como mídia, escolas, universidades, entre outros (Louro, 2008). Esses espaços vêm se modificando, principalmente através dos meios de comunicação social, aumentando os debates sobre a homossexualidade (Madlener \& Dinis, 2007). Entretanto, os autores questionam, até que ponto esta discussão, que poderia ter um caráter inovador e transformador, serve aos ideais de uma sociedade normatizadora? São discursos efetivamente inclusivos ou estão precedidos de preconceito?

Atualmente, a homossexualidade é um tema que reúne muitos estudos teóricos e empíricos, especialmente entre as ciências humanas que investigam as diferentes formas de expressão dessa orientação sexual e o impacto social que provoca. Tais repercussões apontam para um contexto que ainda discrimina o homossexual e o coloca à margem da sociedade (Costa, 2007; Maffesoli, 2007; A. S. Silva, 2007; V. G. Silva, 2007).

Ainda assim, a luta dos homossexuais para ter seus direitos garantidos frente à Constituição, é depreciada por determinados grupos sociais. Tais grupos criticam a criação de leis específicas com o objetivo de garantir direitos como, legalizar o casamento, constituir família, ter filhos, dividir o plano de saúde, entre outros direitos, privilégio apenas dos casais heterossexuais (Grossi, 2003). Segundo R. R. Rios (2006), é primordial desenvolver o direito democrático da sexualidade e examinar, na perspectiva dos direitos humanos, constitucionais e fundamentais, as diversas normas jurídicas, cujo âmbito de proteção direciona-se às diversas manifestações da sexualidade humana.

Os direitos referidos estão inseridos em um contexto que delimita parâmetros socioculturais para a orientação sexual dos seus membros e que, durante longo tempo, entendeu a heterossexualidade como algo obrigatório, determinado biologicamente. Nesse sentido, a sexualidade era reduzida ao regime binário de masculino e feminino e se configurava como limite entre lícito e ilícito, permitido e proibido (Costa, 2007; Martins-Silva, Souza, Silva, Nascimento, \& Balbi, 2012). Na sociedade contemporânea, a sexualidade é analisada como uma dimensão definidora do indivíduo e imprescindível à formação de uma identidade pessoal (Gouveia, Athayde, Soares, Araújo, \& Andrade, 2012).

L. F. Rios (2012) examinou a formação dessas identidades em contextos específicos por meio de uma pesquisa de base etnográfica com observações participante e entrevistas. $\mathrm{O}$ estudo envolveu sentidos e valores relativos aos homens com práticas homossexuais em casas de candomblé dos subúrbios do Rio de Janeiro e da Baixada Fluminense. Em tais locais, as articulações entre performances de gênero e trabalho religioso constituíam estilos de ser homem e determinavam uma hierarquia. $\mathrm{O}$ autor identificou que os homossexuais masculinizados (okós) assumiam posições de destaque no terreiro-mundo e eram respeitados pelo grupo, o que não acontecia aos indivíduos efeminados (adés).

Os resultados dessa pesquisa corroboram outros estudos (A. A. Souza, Cerquinho, Nogueira, \& Melo, 2013; E. M. Souza \& Pereira, 2013) sobre a discriminação que existe entre os próprios homossexuais. Segundo esses autores, a discriminação entre os indivíduos do mesmo sexo, está associada aos complexos dispositivos de poder utilizados para hierarquizar os grupos sociais, sendo o heterossexual superior/dominante e o homossexual inferior/dominado. Tais percepções são produzidas pelas relações de poder que se constituem por de meio de processos de subjetivação. O indivíduo homossexual aceitaria então, nessa construção social, continuar invisível aos olhos da sociedade e construindo uma realidade paralela.

Para alguns autores, a sociedade demonstra nítida rejeição à livre orientação sexual e torna a sexualidade uma definidora de papéis sociais (Dias, 2005; Madlener \& Dinis, 2007; L. F. Rios, 2012). Estar alinhado ao sistema sexo-gênero implica em moldar-se de acordo com elementos normatizadores, que vão desde posições de traba- 
lho e gestualidade, até adereços corporais. Nesse sentido, ser do sexo masculino e se apresentar socialmente com traços efeminados, implica em não estar disponível e ser aceito em muitas atividades e postos de trabalho (L. F. Rios, 2012). De acordo com pesquisa de Gouveia et al. (2012) as motivações do agir sem preconceito estão associadas às necessidades individuais e às demandas da sociedade, que determinam posturas pessoais e asseguram um ambiente estável e seguro ou de hostilidade e rejeição.

Uma vez que a feminilidade nos corpos masculinos pode acarretar preconceito e ser determinante nos lugares ocupados socialmente, o indivíduo é privado de expressar sua subjetividade enquanto direito individual, social e difuso. Dessa forma, nascem performances situacionais de gênero que apresentam-se como a modulação de identificações de gênero a partir do modelo homem e mulher. E, do engessamento e enquadramento das definições de orientação sexual, emerge a segregação social e o preconceito, promovendo a heterossexualidade e estimulando o desrespeito e a homofobia, como se a orientação sexual não fizesse parte da dignidade humana (L. F. Rios, 2012; R. R. Rios, 1998; A. A. Souza et al., 2013; E. M. Souza \& Pereira, 2013).

Dessa forma, entre os desafios encontrados durante a busca de legitimação pelo direito de ser diferente da maioria (V. G. Silva, 2007), o indivíduo homossexual enfrenta, muitas vezes, situações aversivas no próprio ambiente de trabalho para permanecer no emprego e ter chances de ascensão profissional (A. A. Souza et al., 2013). Além disso, os autores referem que o assédio moral e a discriminação no ambiente de trabalho, por meio de ofensas verbais, é um acontecimento que o homossexual nem sempre reconhece e, quando consegue identificar, precisa subjugar-se à situação para se manter no emprego.

Nas instituições religiosas, outro segmento social, os homossexuais são percebidos, muitas vezes, como desajustados da natureza. Tais instituições impõem à família a responsabilidade única da procriação e desconsideram o relacionamento entre pessoas do mesmo sexo, como se elas fossem incapazes de constituir uma família, ter filhos e levar uma vida digna. Ademais, alguns setores da sociedade ligados às igrejas, promovem campanhas em prol, exclusivamente, das configurações familiares tradicionais por meio de ataques homofóbicos (Louro, 2008), e reafirmam, assim, um perfil conservador, matrimonializado, patriarcal, indissolúvel e historicamente heterossexual (Dias, 2008).

De acordo com Frigo et al. (2014) o preconceito, a discriminação e o constrangimento, são fatos cotidianos na vida de muitos homossexuais. Tais situações acontecem por meio de violência verbal, psicológica e física em diversos segmentos sociais, entre eles, escolas, bares, serviços de saúde, instituições religiosas, instituições públicas e organizações privadas. São atos praticados por pessoas da família, por amigos, por colegas de trabalho e por pessoas desconhecidas.

Nesse universo em que o indivíduo homossexual não possui uma referência que o localiza no mundo social, pode ocorrer o que Costa (2007, p. 8) denominou de perda de um "sentido de si" estável, constituindo uma crise de identidade. Esse entendimento corrobora $\mathrm{Nu}$ nan (2010) sobre o preconceito internalizado e a autodestruição por meio de comportamentos de risco, enquanto possíveis repercussões da condição de marginalização do homossexual. Segundo a autora, os riscos de contrair doenças sexualmente transmissíveis e HIV estão associados aos reforçamentos do preconceito institucionalizado no próprio indivíduo homossexual, como uma espécie de profecia autorrealizadora do seu futuro.

Noutra perspectiva, Lomando, Wagner e Gonçalves (2011) realizaram uma pesquisa com 111 pessoas homossexuais com o objetivo de investigar a correlação entre a coesão e a adaptabilidade conjugal e a percepção de apoio social da família, dos amigos e das relações de trabalho/escola. Os resultados apontaram que a família demonstra, atualmente, maior flexibilidade para aceitar a homossexualidade. $\mathrm{O}$ ambiente familiar é compreendido, segundo o estudo, como um espaço de acolhimento e de diálogo, apresentando-se de maneira menos defensiva e abrindo-se à possibilidade de revelação da homossexualidade. 
Em uma pesquisa sobre a homossexualidade adolescente, realizado por Taquette, Vilhena, Santos, e Barros (2005), em um ambulatório de saúde, os pesquisadores identificaram nos relatos dos jovens extrema dificuldade de verbalizar suas experiências homossexuais. Ainda, aqueles adolescentes que declaravam-se homossexuais entendiam que sua orientação sexual era a causa das dificuldades enfrentadas na sociedade. Segundo os autores, o resultado demonstrou o aparente lugar social de preconceito e a imagem da homossexualidade como algo perverso e pecaminoso, uma transgressão da norma.

Nesse sentido, a revelação da orientação sexual é um desafio significativo para o indivíduo, temeroso quanto à reação dos seus familiares e da sociedade. Sente-se a angústia por frustrar as expectativas da família, contrariando, por meio da homossexualidade, uma construção sociocultural a respeito de si mesmo e do homem heterossexual que deve afirmar-se dentro de uma sociedade racionalizadora, patriarcal, higienizada e dedicada a banir qualquer tipo de ameaça de grupos minoritários (Frigo et al., 2014; Maffesoli, 2007; V. G. Silva, 2007).

Desse modo, a família é apontada como o maior alicerce para que o indivíduo possa assumir a sua orientação sexual perante a sociedade e para si mesmo (Frigo et al., 2014). Além disso, segundo Lomando et al. (2011), a família e os amigos são a principal rede de apoio nas relações amorosas homossexuais, tanto para as mulheres quanto para os homens e, ainda, que tal relevância não é exclusiva dos homossexuais, mas também fazem parte dos relacionamentos heterossexuais.

Diante do exposto, fomentar outras reflexões sobre o tema da homossexualidade masculina, na perspectiva do próprio indivíduo, poderá contribuir para a compreensão das relações que se estabelecem entre o homossexual e o contexto onde está inserido, nomeadamente, a família, o trabalho, a escola e os grupos de amigos. Para tanto, o objetivo deste estudo foi compreender as percepções do homossexual masculino sobre a sua orientação sexual e as possíveis repercussões da sua homossexualidade no contexto familiar e social onde vive.
Método

\section{Delineamento}

Trata-se de uma pesquisa qualitativa com delineamento exploratório e descritivo.

\section{Participantes}

A pesquisa contou com quatro participantes homossexuais do sexo masculino e maiores de idade. Os critérios de exclusão foram homossexuais menores de idade, pessoas do sexo feminino e heterossexuais.

\section{Instrumento}

Entrevista semiestruturada com questões norteadoras que buscaram investigar a percepção dos participantes acerca das relações familiares, sociais e profissionais, da revelação da homossexualidade à família e aos amigos, bem como, a auto percepção da sua homossexualidade.

\section{Coleta de Dados}

Os participantes foram selecionados por conveniência, através da indicação de pessoas da rede de contato dos pesquisadores. Os quatro indicados foram contatados por telefone, informados do objetivo do estudo e convidados a participar da pesquisa. Diante do aceite, as entrevistas foram agendadas segundo a disponibilidade de cada participante e ocorreram em sala reservada na instituição de ensino. Não emergiram novas informações a partir da quarta entrevista, identificando-se saturação dos dados e, portanto, encerrando-se a coleta. As entrevistas realizadas foram gravadas em áudio e tiveram duração aproximada de 40 minutos.

\section{Análise de Dados}

As entrevistas foram transcritas integralmente e o material submetido à análise de conteúdo, técnica que utiliza um conjunto de procedimentos sistemáticos, explícitos e replicáveis através dos quais são feitas inferências válidas de um texto (Gibbs, 2009). As etapas da análise foram: (a) Leitura detalhada e repetida do material transcrito com o objetivo de conhecer integralmente o texto; (b) Identificação das uni- 
dades de sentido; (c) Categorização temática das unidades de sentido definidas a posteriori; (d) Identificação de intenções particulares, considerando o conteúdo das falas, a interpretação e as inferências a partir da experiência do pesquisador (Bardin, 2009).

\section{Procedimentos Éticos}

O estudo foi aprovado sob o protocolo de número 004/2010 pelo comitê de ética em pesquisa da Instituição de Ensino onde a pesquisa foi realizada. Os participantes leram e assinaram o termo de consentimento livre e esclarecido TCLE. No termo, os participantes foram informados que poderiam desistir de sua participação antes de assinar o TCLE, sem nenhum prejuízo, e que os riscos que corriam era sentirem-se mobilizados emocionalmente durante a entrevista, sendo, nestes casos, avaliada cada situação e feito o encaminhamento para atendimento na Clínica Escola da Instituição de Ensino. Além disso, foram assegurados os cuidados éticos em todos os procedimentos de pesquisa envolvendo seres humanos, conforme as diretrizes e normas regulamentadoras que constam nas Resoluções 466/2012 do Conselho Nacional de Saúde (2012) e 016/2000 do Conselho Federal de Psicologia (2000).

\section{Resultados e Discussão}

Os participantes do estudo têm as seguintes características: o primeiro entrevistado (P.1), tinha 31 anos de idade, era solteiro, possuía ensino superior completo e trabalhava como professor de língua estrangeira. P.1 residia com o pai, a mãe, um irmão com 26 anos e a cunhada. O segundo participante (P.2) tinha 19 anos, era solteiro, possuía ensino médio completo e não trabalhava. P.2 era filho único e morava com o pai, a mãe, os avós paternos, um tio também pelo ramo paterno, a esposa do tio e o primo. O terceiro entrevistado (P.3), tinha 25 anos de idade, era solteiro, apresentava ensino médio completo e trabalhava como sub gerente na área de vendas. P.3 morava com o pai, a mãe e a irmã de dezenove anos. $\mathrm{O}$ último participante (P.4), tinha 23 anos de idade, era solteiro, cursava a faculdade de Designer e trabalhava como designer gráfico. P.4 referia que os seus pais eram separados e que residia com a mãe e a irmã de trinta e um anos.

Por meio da análise de conteúdo emergiram quatro eixos temáticos: Eixo I - Amizade: vínculo para ser quem realmente somos; Eixo II - Comportamentos e sentimentos do homossexual; Eixo III - Percepção pessoal da homossexualidade e revelação para a família; Eixo IV - Repercussões da revelação da homossexualidade na família.

\section{Amizade: Vínculo para Ser Quem Realmente Somos}

Os entrevistados relataram que, quanto mais intimidade, mais naturais conseguem ser nas relações interpessoais que cultivam. Os relacionamentos sobre os quais os entrevistados se referiram foram aqueles cultivados no ambiente de trabalho, nos grupos artísticos e na rede de amigos mais próximos. Neste último grupo, a relação de amizade envolvia frequentar a casa e manter um contato mais estreito com outros membros da família dos participantes. Estes grupos, segundo eles, são formados tanto por heterossexuais, quanto por homossexuais.

Os participantes disseram: P.2: "eu acho que não muda assim com meus amigos intimos heterossexuais e homossexuais, eu diria que não é diferente"; P.4: "brincadeiras com pessoas mais íntimas ou não, não deixo de ser eu da mesma forma que eu tô falando com você, porém quando é mais intimo pode brincar um pouco mais, mas não ajo diferente"; P.3: "tenho amigos heteros que frequentam minha casa, tanto é que meus amigos heteros são os mesmos amigos dos meus amigos homossexuais. Para mim, isso nunca teve nenhum tipo de problema"; P.1: "muda um pouco a postura . . . Eu não vou ter o mesmo comportamento com meus amigos íntimos, isso é óbvio [sic]".

Pode-se compreender que, nas relações de amizade, quanto mais significativo o grau de intimidade, mais abertura para tratar de temas de cunho privado e agir com espontaneidade; sobretudo nestes casos, porque o laço afetivo aproxima e pode permitir olhar para além da orientação sexual. Entretanto, talvez tal questão não 
seja exclusiva de homossexuais e relacionada à sexualidade; afinal, a confiança, a confidencialidade e os comportamentos espontâneos acontecem, geralmente, quando há intimidade (Lomando et al., 2011).

\section{Comportamentos e Sentimentos do Homossexual}

Essa categoria refere-se aos comportamentos e aos sentimentos do indivíduo homossexual. Os participantes disseram que o ambiente condiciona o comportamento devido às dificuldades que as pessoas possuem de olhar o homossexual como uma pessoa igual às demais. Foi referido pelos entrevistados:

P.3: eu sou a mesma pessoa em todos os lugares só que em alguns, sou bem mais discreto. A postura é diferente, bem diferente, por exemplo, eu fico um machinho como a gente costuma dizer né, eu fico um bofe, um homem, engrosso a voz, quando é pra frequentar um lugar que eu não conheço, que eu não sei as pessoas que vão estar ali, eu fico mais discreto, bem na minha, até conhecer mais as pessoas, depois que conheci aifoi.

P.1: "se descobrirem que você é gay você vai perder o emprego, ninguém mais vai te contratar, então eu tinha esse medo".

P.2: nunca sofri nenhum tipo de preconceito, mas também porque nunca sai na rua com uma placa dizendo que sou gay, talvez se tivesse feito isso teria sido diferente . . . Minha vida pessoal com certeza é diferente porque pela minha sexualidade né.

P.4: "às vezes quando você é olhado assim eu me sinto um pouco inferior [sic]".

De acordo com os dados encontrados, existem contextos em que se faz distinção entre pessoas heterossexuais e homossexuais. Para os entrevistados, é necessário observar a postura, em algumas situações, para se proteger do possível preconceito e até de consequências, como a perda do emprego, corroborando outros autores (A. A. Souza et al., 2013; E. M. Souza \& Pereira, 2013). Além disso, a conduta dos participantes pode ser uma tentativa de evitar situações cons- trangedoras e reações imprevisíveis de pessoas que, muitas vezes, expõem sua opinião quanto à homossexualidade de forma desrespeitosa e agressiva. Entretanto, tais comportamentos protetivos, a priori, podem apontar para o que Gouveia et al. (2012) e L. F. Rios (2012) denominaram de auto discriminação, em que os próprios indivíduos advertem homossexuais que expressam livremente sua orientação sexual, tornando-se visível socialmente.

Algumas reflexões acerca desse resultado podem apontar para um contexto social normativo, por vezes, heteronormativo corroborando outros estudos encontrados (Maffesoli, 2007; A. S. Silva, 2007; V. G. Silva, 2007). Como se discutiu na categoria anterior, tais normas de comportamento existem para todas as pessoas. Cada contexto, seja ele profissional, familiar, social, entre outros, exigirá determinada postura congruente à situação. Entretanto, a percepção dos participantes acerca do cuidado em termos de comportamento pode refletir também o sentimento dessas pessoas que, por vezes, se colocam nessa postura vigilante como se estivessem sendo observadas.

Através das experiências que esses indivíduos tiveram junto à família de origem e diferentes grupos, podem ter sido construídas concepções de mundo que os levam a agir retroalimentando as novas relações que se constituem, permanecendo um mesmo padrão interacional. Dessa forma, os discursos podem apontar para relações entre indivíduo e sociedade que se complementam, se atualizam e se "re"constituem, porém, sem avanços muito expressivos em termos de igualdade, conforme apontam outros autores (Costa, 2007; Frigo et al., 2014; Louro, 2008; Madlener \& Dinis, 2007; Martins-Silva et al., 2012).

Além disso, os participantes do presente estudo referiram sentimentos de desajustamento, de culpa, de inferioridade, de medo e de receio quanto ao que outras pessoas, conhecidos, amigos, familiares iriam pensar. Foi dito por eles: P.1: "eu tinha muito medo do que os outros iriam pensar de mim"; P.2: "você vê uma coisa que não é mostrada naturalmente para nós, para 
a sociedade, e você percebe que você é assim e que nada pode mudar, não foi fácil, com certeza não"; P.3: "eu me sentia bem para baixo . . . Uma culpa, uma dor aqui dentro assim que só eu sei”; P.4: "uma confusão só porque assim, você via as meninas, você via seus amigos ficando, aquela reação toda, e você não sentia a mesma coisa [sic]".

Diante desse resultado, pode-se pensar o que provocou os sentimentos que os participantes disseram. Uma possibilidade é de que eles estejam associados aos estereótipos do que é esperado socialmente, em termos de etapa do desenvolvimento de um menino heterossexual e ao que a família, especialmente as figuras parentais, esperam desse filho. Segundo os estudos (Frigo et al., 2014; Maffesoli, 2007; V. G. Silva, 2007), espera-se que o menino seja forte, não chore, se interesse por meninas, goste de brincadeiras de homem, entre outras coisas. Os pais sonham que o menino seja bem sucedido profissionalmente $\mathrm{e}$ que tenha filhos para dar continuidade ao sobrenome da família.

Quando o menino, mais tarde, se descobre homossexual, percebe que não se encaixa em muitas das características que deveria ter, segundo preceitos familiares e sociais. Inicia-se, então, um processo interno de "des"ajustamento e "des"construção que provoca profundo sofrimento, já que existe uma contradição entre o mundo interno e o mundo externo do homossexual que, muitas vezes, sente, pensa e é diferente do grupo de iguais, conforme os participantes relataram (Costa, 2007; Nunan, 2010).

\section{Percepção Pessoal da Homossexualidade e Revelação para a Família}

Neste eixo temático discute-se o momento em que o próprio indivíduo se dá conta da sua homossexualidade e a revelação da orientação para a família. Quanto à percepção da própria orientação, os participantes disseram: P.1: “eu sempre soube, desde que eu tenho consciência sobre mim, eu sempre soube. Sabia que eu era diferente, e aos poucos, eu fui vendo qual era a diferença na verdade"; P.2: "eu perdi a virgindade com um homem aos treze anos, mas não foi nada forçado, tanto eu queria quanto ele, e daí, a partir dai [pausa]. Não, antes mesmo eu já sabia que era gay [sic]".

Por meio dos relatos, percebe-se que identificar o momento em que o indivíduo se descobriu homossexual é algo difícil ou até mesmo impossível. Uma compreensão para esse resultado é a de que a percepção pessoal da orientação sexual não é uma necessidade do próprio indivíduo que se desenvolveria conforme seu instinto e características biopsicossociais. Entretanto, devido aos condicionamentos culturais e sociais, o sujeito precisa se justificar por ser diferente, por fugir à norma ou, de alguma forma, romper padrões estabelecidos, seja na esfera sexual, estética, familiar, entre outras (Frigo et al., 2014; Maffesoli, 2007; V. G. Silva, 2007).

A revelação da homossexualidade aconteceu de forma muito particular em cada grupo familiar. Os entrevistados disseram P.2: "aos treze anos eu já contei para minha mãe, pro meu pai, para a família e tal. Era bem complicado, não foi nada fácil, talvez tenha sido a pior época da minha vida".

P.3: uma noite nós estávamos na minha casa, só eu e minha mãe, também tomei um porre porquê a bebida abre a minha boca e sai, dai eu quis contar e conversar com a minha mãe sobre tudo, da minha vida inteira, daí eu contei tudo. Ela [a mãe] começou a ficar muito culpada, ai eu falei que ela não tinha que ficar tão triste.

P.4: para minha mãe foi mais dificil. Ela chorou bastante e disse que foi uma decepção muito grande, assim na hora sabe? Dai eu evitei algumas coisas, exclui algumas coisas que ela falou porque foram doloridas, digamos assim. Eu acho que talvez pelo grau de escolaridade dela, por viver sempre no interior, por não ter contato com isso, então eu acho que é bem difícil, a cabeça é ainda um pouco fechada [sic].

Além disso, dois participantes disseram desconfiar que os familiares já sabiam da homossexualidade:

P.1: é um processo, já pensei bastante sobre isso, mas foi um processo de vinte e seis 
vinte e sete anos, não aconteceu assim da noite para o dia, na verdade eu acho que eles sempre souberam e sabiam antes mesmo de eu saber, só que tem tantas barreiras e coisas que acontecem que né, eles, a gente acaba ocultando.

P.3: semana passada minha mãe me contou que meu pai falou pra ela "ele tendo estudo e trabalho, não interessa se ele estiver com homem, se tiver com mulher". Por isso eu estou com uma pulguinha atrás da orelha, desde a semana passada, eu pensei, nossa, é bom saber disso né [sic].

Através dos relatos, percebe-se que a decisão e a iniciativa quanto a revelação da orientação sexual pareceu ser realmente difícil para os participantes. Pode ser que tal momento envolva uma série de emoções tanto naquele que revela quanto na família e que poderão ser mais ou menos intensos, variando segundo as crenças pessoais e culturais de cada família e as formas através das quais enfrenta as novas situações, corroborando outros estudos (Frigo et al., 2014; Taquette et al., 2005).

O sentimento de dois entrevistados de que os familiares já sabiam da homossexualidade pode ser verdadeiro visto que os pais, normalmente, conhecem muito bem seus filhos. Entretanto, por desconhecimento, por não saber como lidar com a situação ou porque ao saber é necessário se posicionar, muitos pais e familiares não tocam no assunto até que seja inevitável.

Segundo os participantes, quando existem outros homossexuais na família, torna-se mais fácil relevar a própria orientação sexual. Os entrevistados disseram P.2: "então foi mais fácil pelo fato de já ter um homoafetivo na familia"; P.3: "na família por parte de mãe eu tenho uma tia que é homoafetiva e um tio, então no lado materno é bem mais fácil. Até me deram apoio quando fui contar para a minha mãe [sic]". O fato de existir outros homossexuais na família pode ter reduzido o impacto da notícia uma vez que não se tratava mais de uma realidade desconhecida daquele núcleo familiar. Além disso, assumir a orientação sexual quando se tem alguém próximo em quem se apoiar ou com quem se comparar pode fazer o indivíduo se sentir menos temeroso e solitário para gerenciar as emoções e o impacto que a notícia provocará dentro da família (Balderston, 2014; Louro, 2008).

\section{Repercussões da Revelação da Homossexualidade na Família}

Neste eixo são apresentadas as repercussões da revelação da homossexualidade na família. Segundo os entrevistados, contar sobre a homossexualidade proporcionou novas formas de interação entre eles e os membros da família: P.1: "teve até aproximação com algumas pessoas, os laços se solidificaram mais"; P.3: "eu me continha, falava grosso e depois eu comecei a brincar mais"; P.4: "digamos assim, ela [mãe] passou a me dar apoio, me apoiar e me aceitou. Eu passei a existir de uma certa forma, eu passei a existir, era como se eu fosse invisivel [sic]".

Por meio dos dados coletados, é possível compreender que a revelação da homossexualidade provocou uma alteração nos padrões de interação familiar e nos sentimentos dos participantes, que não precisaram mais esconder a sua orientação sexual ou se esconder devido a ela. A existência de segredos na família tenciona as relações, engessa a espontaneidade e cria barreiras para que o segredo seja mantido, provocando distancias entre os membros da família. Nesse sentido, revelar a orientação sexual provocou uma alteração no jeito de agir do próprio indivíduo e no tratamento que recebia dos familiares, alterando, assim, os padrões de interação e a dinâmica familiar (Lomando et al., 2011).

Além disso, os entrevistados disseram que os familiares demonstram uma série de preocupações ao saber da homossexualidade. A apreensão familiar envolve principalmente sofrer preconceito, contrair doenças sexualmente transmissíveis, ser vítima de pessoas mal intencionadas e não ter o futuro sonhado pelos pais. Os participantes disseram:

P.1: eles tem muito medo assim de casos que ouvem falar de gays que foram mortos por se envolver com pessoas perigosas, e o medo deles assim é esse, de eu me relacionar com pessoas que não são boas, 
sei lá, marginais, alguma coisa do tipo, esse é realmente o medo deles.

P.2: "de eu sofrer algum tipo de preconceito durante a minha vida"; P.3: "eles querem que eu trabalhe, que eu tenha um futuro, faça uma faculdade, meu pai falou que tem que ver o futuro"; P.4: "o que minha irmã me passou em relação ao preconceito que eu iria enfrentar, que algumas pessoas poderiam se aproveitar, ou seja, outros homens poderiam se aproveitar, devido a doenças [sic]".

Exceto pela referência ao preconceito, relacionado especificamente à orientação sexual, as preocupações dos familiares, especialmente dos pais, não são exclusivas apenas quando o filho é homossexual. Os pais normalmente querem proteger os filhos, traçam planos para suas vidas e sonham com um futuro promissor. Quanto ao preconceito, de fato a homossexualidade é tema de muitas discussões e, por mais que atualmente existem leis garantindo os direitos dos homossexuais e a comunidade LGBT (lésbicas, gays, bissexuais e travestis/transexuais) tenha conquistado um espaço social e midiático importante, muito ainda precisa ser feito para se pensar efetivamente em igualdade e liberdade (Frigo et al., 2014; Grossi, 2003; R. R. Rios, 2006). Nesse sentido, a preocupação que os participantes relataram por parte da família é uma questão atual e relevante (Nunan, 2010).

\section{Considerações Finais}

O objetivo do presente estudo foi compreender as percepções do homossexual masculino sobre a sua orientação sexual e as possíveis repercussões da sua homossexualidade no contexto familiar e social onde vive. A partir dos relatos dos entrevistados, identificou-se que os homossexuais constituem um grupo de pessoas que busca seu espaço junto à sociedade. Para tanto, explicitam publicamente sua orientação sexual às pessoas mais próximas, como familiares e amigos, que, na percepção dos participantes, aceitam mais facilmente a homossexualidade pela proximidade afetiva que os vincula.
Por outro lado, no segmento profissional e no relacionamento com pessoas desconhecidas, referem ser necessário esconder ou mesmo evitar revelar a orientação sexual para se proteger da discriminação. Tais questões podem estar associadas ao preconceito, às dificuldades de aceitar a diversidade sexual e de se relacionar com indivíduos de diferente orientação sexual.

Os resultados do estudo possibilitam compreender que, apesar das situações discriminatórias, algumas transformações ocorrem lentamente, como a aceitação entre amigos, mesmo aqueles de diferente orientação sexual, e no contexto familiar. Além disso, a preocupação dos familiares está associada, muitas vezes, a um possível sofrimento e preconceito que o indivíduo possa experienciar, preocupação para além da sexualidade. Muitos avanços vêm acontecendo de modo que é possível perceber famílias recebendo a notícia sobre a homossexualidade de forma mais pacífica, flexível e acolhedora. Porém, a sexualidade ainda é normatizada a partir da heterossexualidade. Nesse sentido, a percepção do próprio indivíduo sobre sua homossexualidade é um fator importante para a manutenção ou atualização dos tipos de interação que estabelece devendo, portanto, ser observado.

Por ser uma pesquisa qualitativa, os dados precisam ser discutidos à luz do contexto investigado. Foram percepções de um grupo pequeno de indivíduos, residentes no interior do estado do Rio Grande do Sul, sobre suas vivências, comportamentos e sentimentos dentro de uma realidade bastante específica socioculturalmente. Portanto, mais investimento em termos de pesquisa devem ser feitos a fim de se poder levantar outras discussões e reflexões que efetivamente provoquem mudanças/avanços nas políticas públicas de saúde, na legislação e nos diferentes segmentos da sociedade. Propiciar que a homossexualidade seja reconhecida como uma das formas legítimas de expressão da sexualidade humana é fundamental para que os homossexuais vivam sem se preocupar com as consequências adversas que o seu jeito de ser pode provocar. 


\section{Referências}

Balderston, D. (2014). "Cifro en sangre poema y poesía": el secreto abierto y la tradición homoerótica latinoamericana. Cuadernos de Literatura, 18(35), 198-210. doi:10.11144/Javeriana. CL18-35.cspp

Bardin, L. (2009). Análise de conteúdo. Lisboa, Portugal: Edições 70.

Costa, R. S. M. (2007). Homossexualidade: Um conceito preso ao tempo. Revista Bagoas: Estudos Gays: Gêneros e Sexualidades, 1(1), 1-24. Recuperado em http://www.cchla.ufrn.br/bagoas/ v01n01art06_costa.pdf

Dias, M. B. (2005). Homoafetividade e o direito à diferença. Universo Jurídico, 1. Recuperado em http://www.mariaberenicedias. com.br/uploads/26_-homoafetividade_e_o_ direito_\%E0_diferen\%E7a.pdf

Dias, M. B. (2008). Família homoafetiva. De Jure: Revista Jurídica do Ministério Público do Estado de Minas Gerais. Recuperado em https:// aplicacao.mpmg.mp.br/xmlui/bitstream/handle/123456789/204/familia\%20homoafetiva Dias.pdf?sequence $=1$

Foucault, M. (2006). Microfisica do poder. São Paulo, SP: Graal.

Frigo, J., Zocche, D. A., Vidori, J., Marin, S. M., Prado, G. P., \& Klein, M. L. (2014). Políticas públicas de saúde frente às necessidades dos homoafetivos: Reflexão da práxis de enfermagem. Brazilian Journal of Surgery and Clinical Research, 6(1), 28-33. Recuperado em http://www.mastereditora.com.br/periodico/20140514_1907412.pdf

Gibbs, G. (2009). Análise de dados qualitativos. Porto Alegre, RS: Artmed.

Gouveia, V. V., Athayde, R. A. A., Soares, A. K. S., Araújo, R. C. R., \& Andrade, J. M. (2012). Valores e motivações para responder sem preconceito frente a homossexuais. Psicologia em Estudo, 17(2), 215-225. doi:10.1590/S141373722012000200005

Grossi, M. P. (2003). Gênero e parentesco: Famílias gays e lésbicas no Brasil. Cadernos Pagu, 21, 261-280. Recuperado em http://www.scielo.br/ pdf/cpa/n21/n21a11.pdf

Lomando, E., Wagner, A., \& Gonçalves, J. (2011). Coesão, adaptabilidade e rede social no rela- cionamento conjugal homossexual. Psicologia: Teoria e Prática, 13(3), 95-109. Recuperado em http://pepsic.bvsalud.org/scielo.php?script=sci arttext\&pid=S1516-36872011000300008\&lng $=$ $\mathrm{pt} \&$ tlng $=\mathrm{pt}$

Louro, G. L. (2008). Gênero e sexualidade: Pedagogias contemporâneas. Pro-Posições, 19, 2(56), 17-23. Recuperado em http://www.scielo.br/ $\mathrm{pdf} / \mathrm{pp} / \mathrm{v} 19 \mathrm{n} 2 / \mathrm{a} 03 \mathrm{v} 19 \mathrm{n} 2 . \mathrm{pdf}$

Madlener, F., \& Dinis, N. F. (2007). A homossexualidade e a perspectiva foucaultiana. Revista do Departamento de Psicologia: UFF, 19(1), 4960. doi:10.1590/S0104-80232007000100004

Maffesoli, M. (2007). Homossocialidade: Da identidade às identificações. Revista Bagoas: Estudos Gays: Gêneros e Sexualidades, 1(1), 15-25. Recuperado em http://www.cchla.ufrn.br/bagoas/ v01n01bagoas01.pdf\#page $=15$

Martins-Silva, P. O., Souza, E. M., Silva, A., Jr., Nascimento, D. B., \& Balbi, R. R. Q., Neto. (2012). Adolescentes e homossexualidade: Representações sociais e identidade social. Cadernos de Pesquisa, 42(146), 474-493. doi:10.1590/ S0100-15742012000200009

Nunan, A. (2010). Preconceito internalizado e comportamento sexual de risco em homossexuais masculinos. Psicologia Argumento, 28(62), 247259. Recuperado em https://www.google.com. $\mathrm{br} / \mathrm{url}$ ? sa $=\mathrm{t} \& \mathrm{rct}=\mathrm{j} \& \mathrm{q}=\& \mathrm{esrc}=\mathrm{s} \&$ source $=\mathrm{web} \& \mathrm{c}$ $\mathrm{d}=2 \&$ ved $=0 \mathrm{CCMQFjAB} \&$ url $=\mathrm{http} \% 3 \mathrm{~A} \% 2 \mathrm{~F} \%$ 2Fwww2.pucpr.br\%2Freol\%2Findex.php\%2FP A\%3Fdd1\%3D3726\%26dd99\%3Dpdf\&ei=bgc LVZC-IomeggTo4ICgDw\&usg=AFQjCNEOuIMGgjAQwz81Mop9ofeVDG_GBg\&sig2=7f5 MdwIEOSSdyIAvtbtXeg

Rios, L. F. (2012). O paradoxo dos prazeres: Trabalho, homossexualidade e estilo de homem no candomblé queto fluminense. Etnográfica, 16(1), 53-74. Recuperado em http://www.scielo. mec.pt/pdf/etn/v16n1/v16n1a03.pdf

Rios, R. R. (1998). Direitos fundamentais e orientação sexual: $\mathrm{O}$ direito brasileiro e a homossexualidade. Revista CEJ, 2(6), 27-39. Recuperado em http://www2.cjf.jus.br/ojs2/index.php/cej/ article/view/160/248

Rios, R. R. (2006). Para um direito democrático da sexualidade. Horizontes Antropológicos, 12(26), 71-100. Recuperado em http://www.scielo.br/ $\mathrm{pdf} / \mathrm{ha} / \mathrm{v} 12 \mathrm{n} 26 / \mathrm{a} 04 \mathrm{v} 1226 . \mathrm{pdf}$

Silva, A. S. (2007). As cores memoriais (e distorcidas) da (in)diferença: Com que cores se colorem 
o passado no tempo presente da homofobia?! Revista Bagoas: Estudos Gays: Gêneros e Sexualidades, 1(1), 167-192. Recuperado em http:// www.cchla.ufrn.br/bagoas/v01n01bagoas01. pdf\#page $=167$

Silva, V. G. (2007). A visibilidade do suposto passivo: Uma atitude revolucionária do homossexual masculino. Revista Mal Estar e Subjetividade, 7(1), 71-88. Recuperado em http://pepsic.bvsalud.org/pdf/malestar/v7n1/06.pdf

Souza, A. A., Jr., Cerquinho, K. G., Nogueira, R. J. C. C., \& Melo, D. R. A. (2013). Aspectos da dominação masculina no assédio moral ao profissional homossexual no polo industrial de Manaus. Revista Pensamento \& Realidade, 28(1), 83-103. Recuperado em http://revistas.pucsp. br/index.php/pensamentorealidade/article/ view/15721/11785
Souza, E. M., \& Pereira, S. J. N. (2013). (Re) Produção do heterossexismo e da heteronormatividade nas relações de trabalho: A discriminação de homossexuais por homossexuais. Revista de Administração Mackenzie, 14(4), 76-105. doi:10.1590/S1678-69712013000400004

Taquette, S. R., Vilhena, M. M., Santos, U. P. P., \& Barros, M. M. V. (2005). Relatos de experiência homossexual em adolescentes masculinos. Ciência \& Saúde Coletiva, 10(2), 399-407. doi:10.1590/S1413-81232005000200018

Recebido: 03/06/2012

$1^{a}$ revisão: $16 / 03 / 2015$

Aceite final: 18/03/2015 